\title{
Review: Deformed and recrystallized structures in FCC materials
}

\author{
Purnima Chakravarty ${ }^{a^{*}}$, Jurij Sidor $^{b}$ \\ ${ }^{a}$ ELTE, Faculty of Informatics, Savaria Institute of Technology, PhD student \\ ${ }^{b}$ ELTE, Faculty of Informatics, Savaria Institute of Technology, full professor
}

\begin{abstract}
The evolution in the field of recrystallization related studies in FCC metals is summarized in this paper. The process of recrystallization which is initiated by stored energy is provided by dislocations. However, dislocations are introduced during the process of deformation, hence both aspects are covered, as well as the kinetics of recrystallization is well elaborated. The key features of recrystallization: role of misorientations; deformation and recrystallization textures; are described and most importantly recent issues on recrystallization of FCC metals are documented in this paper. The final remarks contain the future aspects of studies in the field of recrystallization of materials with FCC crystal structure.
\end{abstract}

Keywords: FCC metals, Recrystallization kinetics, Texture evolution

\section{Introduction}

In plastic deformation of metals, dislocations are introduced, and they play a very important role, since the movement of dislocations causes lower deformation energy during the practical forming process of metals compared to one is calculated theoretically for metals without the linear defects [1]. It is possible to explain the mesoscopic changes involved in annealing by means of: nucleation, recovery, recrystallization; that takes place in a metal during the process of annealing in terms of edge dislocations [2].

Annealing is a very important step in the processing route of material. If the material is continuously heated to a high temperature (annealed), thermally activated processes, such as solid-state diffusion, induce mechanisms where the structural defects may be removed or alternatively arranged in configurations of lower energy [3].

Fig. 1 summarizes the major stages of annealing. At the beginning of heat treatment, the point defects are neutralised. The effect of annealing on dislocation is called polygonization as it is presented in Fig. 2. Altogether step-1 to step-3 as described in Fig. 1 is known as recovery $[4,5]$.

Fig. 2 reveals recovery by polygonization of a bent crystal containing edge dislocations. The phenomenon presented in Fig. 1 clearly shows that at the beginning (Fig. 2/a), the deformed metal has dislocations of both positive and negative Burgers vector. With the rise of temperature (Fig. 2/b) the dislocations of opposite signs (pair) annihilate each other leaving behind linear defects of only one type. In annealing, these excess dislocations will arrange into the low-energy configurations in the form of regular arrays or low angle grain boundaries (LAGBs) as it is shown in Fig. 2/c which

(C) ELTE, Faculty of Informatics, Savaria Institute of Technology, 2021

*Corresponding author: Purnima Chakravarty, pc@inf.elte.hu

https://doi.org/10.37775/EIS.2021.2.3 


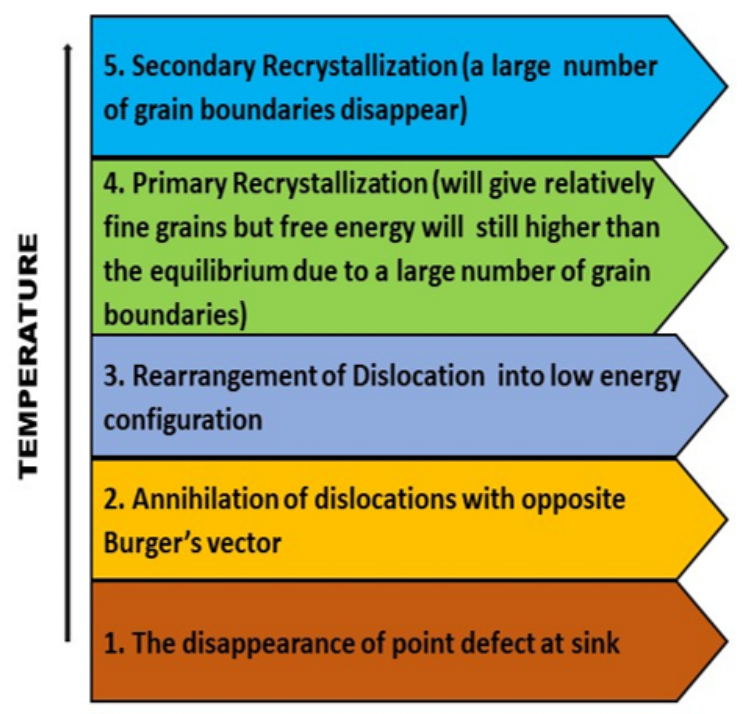

Figure 1. Phenomenon involved in annealing of single-phase metals [3-5]

depicts the phenomenon called polygonization [1, 3]. As shown in Fig. 1, the material shifts towards the process of primary recrystallization (RX) once recovery is over. Recrystallization of the deformed microstructure is known as primary recrystallization to distinguish it from the process of abnormal grain growth which may occur in fully recrystallized material and is sometimes termed as secondary recrystallization, which is revealed by Fig. 3 [3].

It is possible to divide primary RX into two different procedures [3]: (i) Nucleation which corresponds to the first appearance of new grains in the microstructure and (ii) growth during which the new grains replace the deformed structure. The whole process of annealing can be sub-divided into the following steps: a) deformed state, b) Recovery, c) nucleation of new grains, d) partial recrystallization, d) complete recrystallization, e) grain growth and f) abnormal grain growth as shown in Fig. 3.

As metals deformed by the slip mechanism, energy will be accumulated in the material in form of linear defects. During annealing of the material, reduction of the stored energy can take place through relatively slow recovery or by more rapid static recrystallization (SRX). Since recovery proceeds as a continuous process, SRX is a discontinuous process [6].

The process of recrystallization is an extensive transformation phenomenon that is proved to be important in efficient microstructure design. The importance of this process is enhanced due to its capacity to control the structure and properties, specifically structure-sensitive properties of materials [7]. During recrystallization, the deformation in the grain caused by the thermo-mechanical

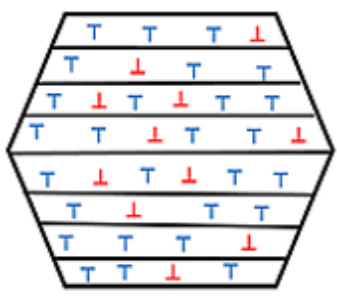

(a)

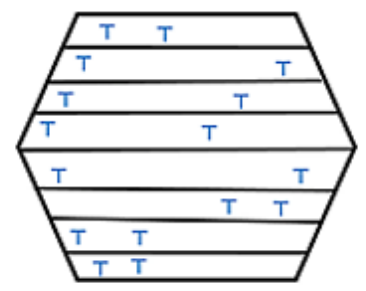

(b)

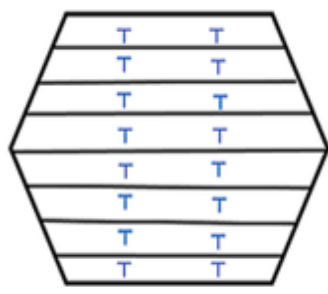

(c)

Figure 2. Schematics explaining the phenomenon of polygonization according to [4, 5]: a) Deformed state, b) dislocation annihilation, c) Formation of dislocation walls 
(a)

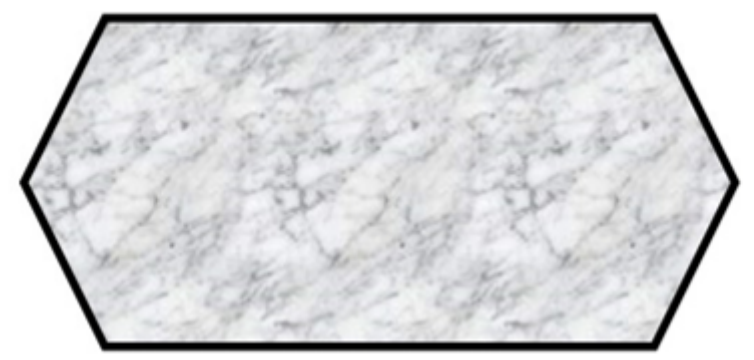

(c)

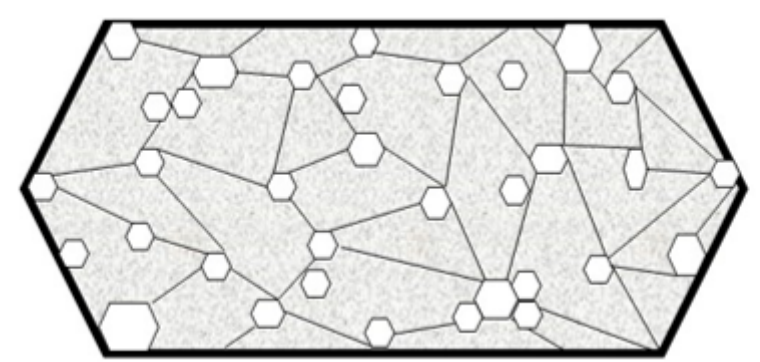

(e)

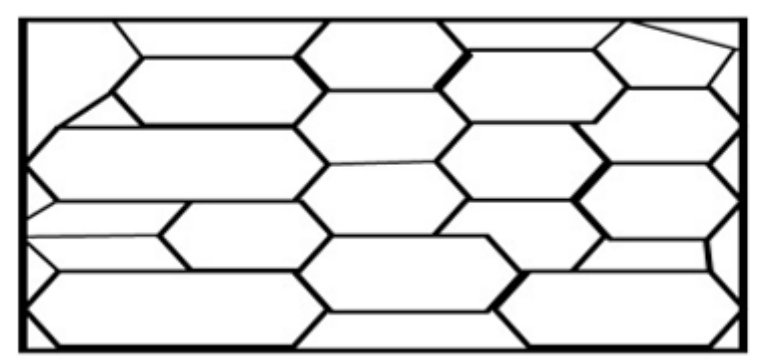

(b)

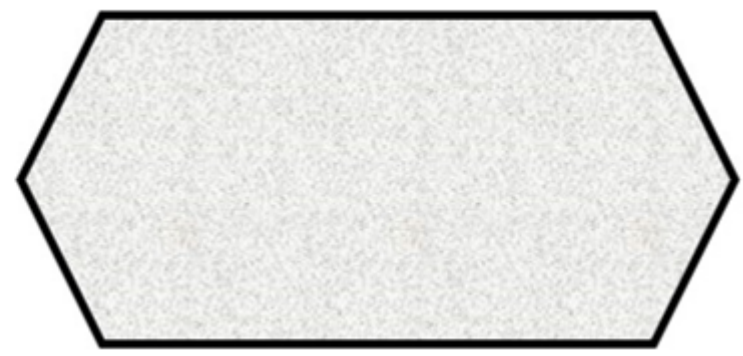

(d)

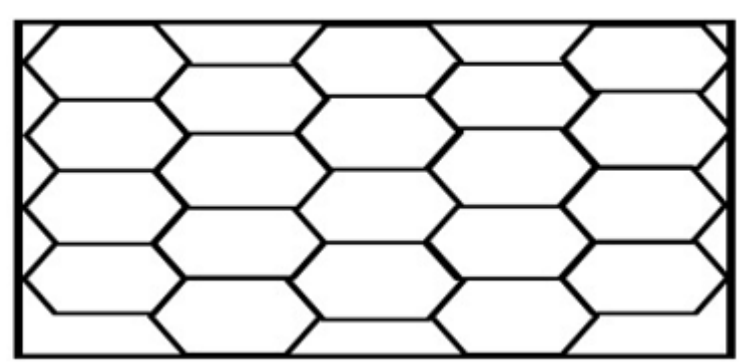

(f)

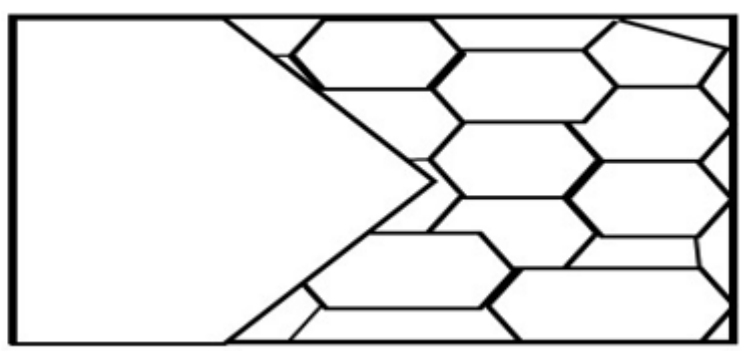

Figure 3. Microstructural changes involved in annealing processes; a) Deformed state, b) Recovered, c) Partially recrystallized, d) Fully recrystallized, e) Grain growth, f) Abnormal grain growth [3]

processing of the material is replaced by new defect-free grains. In short, the recrystallization phenomenon is the corridor towards the development of desirable microstructure as well as the mechanical character of materials [5].

The outcome of annealing process can be seen as the metallurgical changes that return the metal to its pre-cold-worked state. The output of this process results in a reduction of the metal's yield and tensile strength and an increase in its ductility, enabling further cold working. For these changes to occur, the metal must be heated above its recrystallization temperature. However, the recrystallization temperature of a particular metal shows quite a strong composition dependence. The microstructural changes occurring during annealing of a cold-worked metal cause the decrease of stored energy due to plastic deformation. This energy fall is triggered by the mechanisms of rearrangement and annihilation of dislocations (Fig. 2) [7]. It is important to mention that, the factors mentioned above have a direct effect on the recrystallization kinetics.

There is a vast body of experimental evidence and simulation techniques dealing with the structural rearrangements involved in thermomechanical processing of metals. This contribution summarizes the phenomena involved in annealing and analysis the numerical approaches describing the kinetics of recrystallization. 


\section{The kinetics of recrystallization}

The phenomena summarized in Fig. 3 provide a clear picture under the umbrella of the kinetics of recrystallization in terms of Johnson-Mehl Avrami and Kolmogorov (JMAK) equation [8-12]. The qualitative statements on Recrystallization are summarised as laws of Recrystallization, given below $[8-14,16]$ :

- A certain minimum amount of deformation is mandatory to initiate recrystallization process. The deformation must be sufficient to provide a nucleus to begin recrystallization and to provide the necessary driving force for its growth.

- The temperature at which recrystallization takes place decline as the annealing time increases. The correlation between the recrystallization rate and the temperature is given by the Arrhenius type relation.

- The temperature of recrystallization declines as the strain level is elevated. Causing both nucleation and growth process to take place at a lower temperature in a more highly deformed material.

- The size of recrystallized grain depends mainly on the amount of deformation, which is smaller for heavy deformation. Along with that, the number of nuclei or the nucleation rate is much affected by strain in comparison to the growth rate. Hence, a higher strain will provide more nuclei/unit volume causing smaller final grain size. It has been summarized that, for a respective deformation level the recrystallization temperature will increase with: A larger starting grain size. The grain boundaries are considered to be favoured sites for nucleation. Correspondingly, it is clear that a large initial grain size provides fewer nucleation sites, which causes a drop in nucleation rate. The cumulative effect lead either to a slower recrystallization or the process takes place at higher temperatures.

At higher deformation temperatures, more recovery occurs during the deformation (dynamic recovery), which causes lower stored energy than for a similar strain at a lower deformation temperature. Along with the strain path history of the material, the spatial distribution of orientation or grain orientation of the material must play a major role in controlling the rate of recrystallization. The development of microstructure that can be inferred from the textural rotations has an important bearing on the development of annealing textures in cubic metals [15]. On the other hand, recrystallization of different texture components will occur at different rates and will inevitably lead to inhomogeneous recrystallization [14]. The recrystallization kinetics of both copper and silicon-iron single crystals of various orientations, which had been cold rolled $80 \%$, and significant differences in rates of recrystallization has been observed in [16].

Table 1. Recrystallization of silicon-iron single crystals at $600{ }^{\circ} \mathrm{C}[16]$

\begin{tabular}{c|c|c|c} 
Initial orientation & Final orientation & $\begin{array}{c}\text { Time for 50\% } \\
\text { recrystallization [s] }\end{array}$ & $\begin{array}{c}\text { Orientation after } \\
\text { recrystallization }\end{array}$ \\
\hline$\{111\}<112>$ & $\{111\}<112>$ & 200 & $\{110\}<001>$ \\
$\{110\}<001>$ & $\{111\}<112>$ & 1000 & $\{110\}<001>$ \\
$\{100\}<001>$ & $\{001\}<210>$ & 7000 & $\{001\}<210>$ \\
$\{100\}<011>$ & $\{100\}<011>$ & No recrystallization & $\{100\}<011>$
\end{tabular}


Brown and Hatherly (1970) [17] investigated the effect of orientation on the recrystallization kinetics of copper single crystals. In this experiment the FCC system had been rolled to a reduction of $98.6 \%$ and it has been observed that the recrystallization time at $300{ }^{\circ} \mathrm{C}$ varied between 5 and $1000 \mathrm{~min}$ [17]. This is compared with a recrystallization time of 1 minute for a polycrystalline specimen deformed to the same strain. Both $\{110\}<112>$ and $\{110\}<001>$ crystals developed similar $\{110\}<112>$ rolling textures, but due to the differences in the nature of the deformed structure, the former recrystallized 50 times slower [3, 17]. Differences between the recrystallization kinetics and textures of the single crystals and the reference polycrystal in the above investigation, serve to highlight the importance of grain boundaries during recrystallization and show that care must be taken in using data from single-crystal experiments to predict the behaviour of polycrystal [3, 18]. Table 1 depicts the variation of recrystallization rate with orientation significantly [16].

The polycrystalline system also reportedly shows differences in the texture formed after hot rolling and annealing lead to differences in recrystallization kinetics when the material is cold rolled and subsequently annealed [19]. The kinetics of recrystallization is classically addressed by the JMAK relation; which shows a sigmoidal time dependence of recrystallization volume fraction [9-12]:

$$
X_{V}=1-e^{-B t^{n}} .
$$

Here the $X_{V}$ is the fraction of recrystallized grains. The exponent $n$ given by Avrami [12] on the other hand is supposed to depend only on time for the nucleation and growth of recrystallization, temperature independent in nature. In 1979, Sellars [20] reported that the exponent showed independence to temperature and strain rate. If the rates of nucleation and growth remained constant during recrystallization, under such condition $n$ is equal to 4. It is reported by Avrami (1939) [12] that when the rate of nucleation is not constant but rather a decreasing function of time the $n$ varies between 3 and 4, depending on the functional behaviour of nucleation rate.

Under the condition when grains are constrained either by the sample geometry or by some internal microstructural constraint to grow only in one or two-dimensions, then the JMAK exponent are shown in Table 2, which depicts how JMAK exponent varies depending on the growth geometry [3, 7, 12]. Fig. 4 is the pictorial representation of effect of JMAK exponents on recrystallization kinetics. It has been observed, that the depending on the employed JMAK exponent time required for the complete recrystallization varies.

In Eq. (1), term $B$ is defined as:

$$
B=\frac{f \dot{N} \dot{G}^{3}}{4}
$$

Here, $f$ is a shape factor, $4 \pi / 3$ for the sphere. The two factors nucleation rate $\dot{N}$ and growth rate $\dot{G}$ controls the reaction kinetics $[3,7,21]$. It has been assumed that nuclei are formed at a rate:

$$
\dot{N}=\frac{d N}{d t},
$$

where $N$ is nuclei per unit volume during recrystallization. These recrystallization nuclei are the crystallite growing in deformed or recovered material with low internal energy and are separated

Table 2. Ideal JMAK exponents [3, 7, 12]

\begin{tabular}{c|c|c} 
Growth dimensionality & Site saturation & Constant nucleation rate \\
\hline $3-\mathrm{D}$ & 3 & 4 \\
$2-\mathrm{D}$ & 1 & 3 \\
1-D & 2 & 2
\end{tabular}




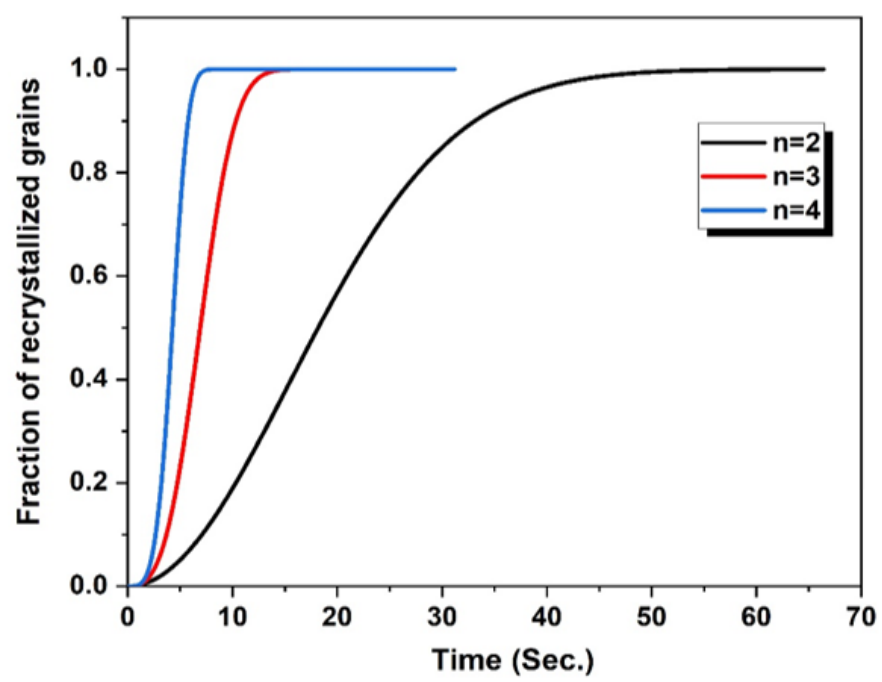

Figure 4. Effect of JMAK exponent on time taken for full recrystallization

by high angle grain boundaries [3, 7, 22]. The growth of new grains is easily detectable during recrystallization. The velocity $(v)$ of a high angle grain boundary, is also defined as the growth rate $(\dot{G})$ :

$$
v=\dot{G}=M P,
$$

where $M$ is the mobility of boundary and $P$ is the net pressure on the boundary. Now, if $P_{d}$ is the driving pressure for recrystallization, offered by dislocation density $\rho$ that produces stored energy $E_{d}$. In this case:

$$
P_{d}=E_{d}=\alpha \rho G b^{2},
$$

where $\alpha$ is constant of the order of 0.5 and $\mathrm{b}$ is the Burger's vector [3, 21]. However, the mobility of grain boundaries $M$ is another important quantity is temperature dependent in nature and is usually found to obey an Arrhenius type relationship of the form

$$
M=M_{o} e^{-Q / R T} .
$$

The slope of a plot of $\ln (M)$ or $\ln (v)$ (for constant $P$ ), against $1 / T$, therefore, yields a value of activation energy $Q$ [3]. The mobility of high angle grain boundaries (HAGB) has a significant relation with the process of recrystallization. It has been observed that during recrystallization of cold-deformed materials, isothermal grain boundary migration rates has decrease with time [23]. HAGB shows orientation-dependent characteristics. For example, it been reported by Cook and Richards (1940) [24] and Bowles and Boas (1948) [25] who found rapid growth of certain orientations

Table 3. Orientation dependency of HAGB as well as growth for some FCC metals [3, 27, 29]

\begin{tabular}{c|c|c|c}
\multicolumn{2}{l|}{ Experimentally established results } & \multirow{2}{*}{ Metal } & Reference \\
\cline { 1 - 1 } Rotation [ ${ }^{\circ}$ ] & Axis & & \\
\hline $35-45$ & $<111>$ & $\mathrm{Al}$ & Liebman et al. (1956) [28] \\
38 & $<111>$ & $\mathrm{Cu}$ & Kronberg and Wilson (1949) [27] \\
$36-42$ & $<111>$ & $\mathrm{Pb}$ & Aust and Rutter (1959) [29] \\
23 & $<100>$ & $\mathrm{Al}$ & May and Erdmann (1959) [3] \\
19 & $<100>$ & $\mathrm{Cu}$ & Kronberg and Wilson (1949) [27]
\end{tabular}




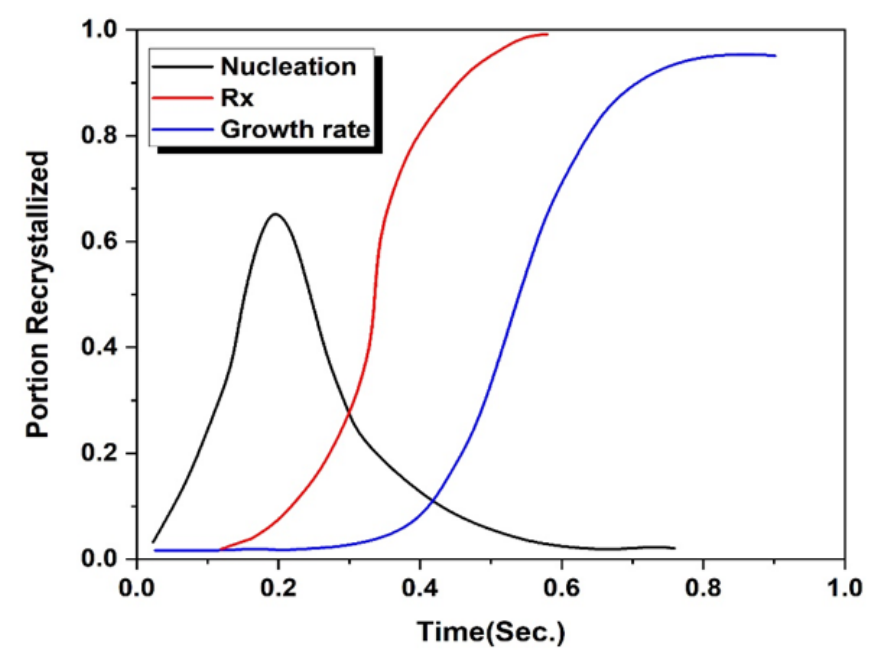

Figure 5. Fraction of recrystallized grains as a function of annealing time for mesoscopic transformations in which temperature is held constant $[5,7,9-12]$

in copper, and Beck et al. (1950) [26] showed that in lightly rolled high purity aluminium, grains with a misorientation of $40^{\circ}$ about the $<111>$ axis exhibited the largest growth rate. Along with this, Kronberg and Wilson (1949) [27] who carried out recrystallization experiments on copper, found that grains related to the deformed matrix by a rotation of $22^{\circ}-38^{\circ}$ about a common $<111>$ axis, and by $19^{\circ}$ about a $<111>$ axis grew most rapidly. The existence of certain orientation relationships which are associated with a rapid growth rate for some FCC metals has been represented in Table 3.

The cumulative effect of all the parameters in Eq. (1) is pictorial represented in Fig. 5. The time required for nucleation to take place and growth of new grains to begin is known as the incubation period. Fig. 5 shows the kinetics of recrystallization (red line) which is a characteristic sigmoidal curve. The rate of recrystallization increases after the incubation period and shows a linear behaviour before slowing down [3]. On the other hand, nucleation rate (black line) increases with time and achieves maximum, finally decreases, enhancing the process of recrystallization [3, 9-12]. The rate of grain growth (blue line) also increases with time resulting in growth of the recrystallized grains in correlation with Fig. 3. Fig. 5 summarizes the standard behaviour of nucleation, growth and

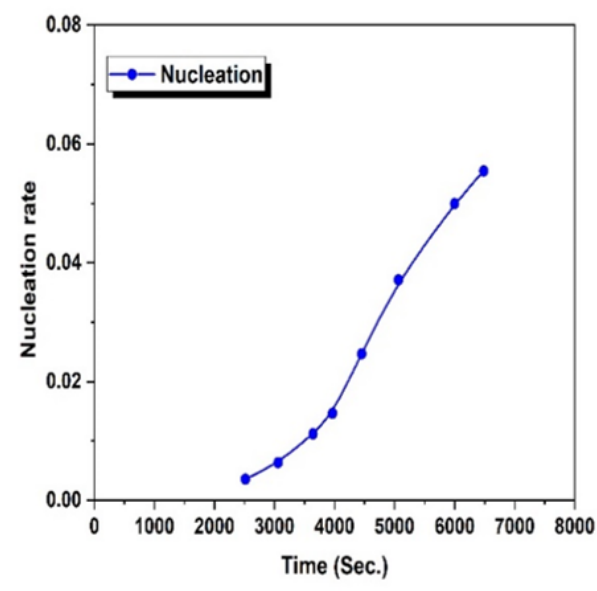

(a)

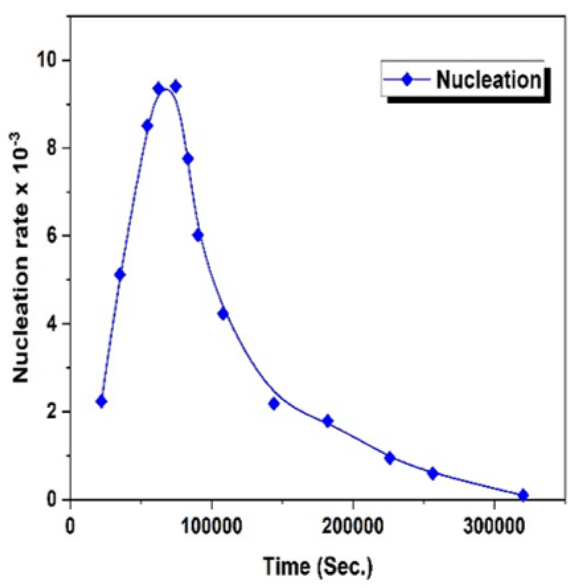

(b)

Figure 6. The changes of nucleation rate $(\dot{N})$ with time for aluminium $5 \%$ deformed, annealed at $350{ }^{\circ} \mathrm{C}$, a) Initial grain size $45 \mathrm{~mm}$ (fine grain), b) initial grain size $130 \mathrm{~mm}$ (coarse grain) [14, 30] 
recrystallization for the metals annealed at constant temperature and a range of time variation [7]. The nucleation rate itself depends on various factors and the major factor is the size of the initial grain, which can be clearly observed in Fig. 6 .

The above two graph shows that depending on initial grain size the nucleation rate shows different behavioural properties. On the other hand, grain growth has various range of dependency factors. The migration of high angle boundaries is the basic mechanism operating during both recrystallization and grain growth [30]. The main difference between them is that the driving force is related to both phenomena. The driving force for grain growth, is the energy of the high angle boundaries, whereas the main driving force for recrystallization is the stored energy, Ed described by Eq. (5). The driving force falls with time during recrystallization, due to simultaneous recovery in the nonrecrystallized regions. However, the process of recovery and recrystallization is competitive and is more pronounced in metals and alloys with both body centered cubic (BCC) crystal structure and face centered cubic (FCC) crystal structure with high Staking fault energy (SFE) [7, 14, 30]. Not only the strain heterogeneity but also the occurrence of recovery may lead to a decrease in the speed of grain boundary migration during recrystallization as well as it can slow down the recrystallization process, which can cause possible deviation in the JMAK equation as shown in Fig. 7 [7].

It can be observed from Fig. 7 that, how different level of deformation can have direct effect on the growth rate of the grains as well as on overall process involved in evolution of stress-free grains. Hence, it can be concluded that there are various factors that can affect nucleation and grain growth and thereby recrystallization kinetics.

As well as there are various methodologies in modelling and simulation of recrystallization. Some numerical formulations discussed in this contribution include continuum mechanical models and discrete approaches such as Monte Carlo Potts models and cellular automata as well as vertex, phase field and level set models [31]. However, the statistical models of primary recrystallization are specifically the superposition model and the compromise model, which has been distinguished by Bunge Kohl (1996) [32]. Both models can describe oriented nucleation, orientation dependence

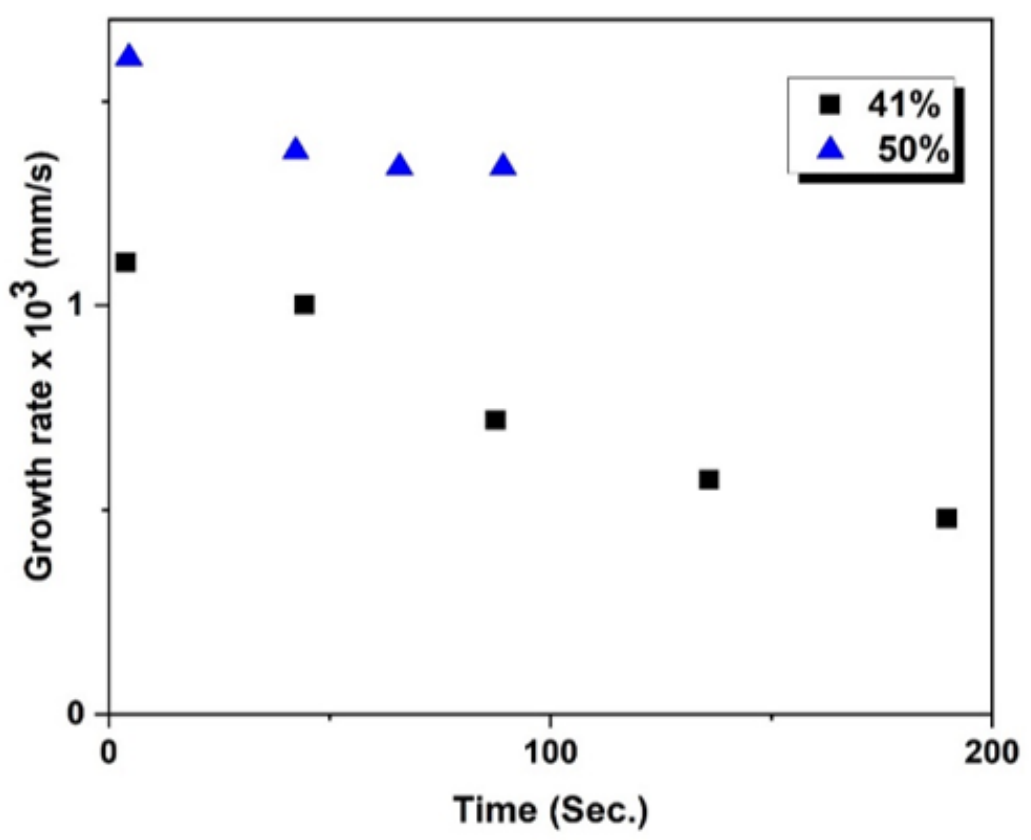

Figure 7. Variation in growth rate in AA3000 Aluminum alloy annealed at $400{ }^{\circ} \mathrm{C}$ with $41 \%$ and deform $50 \%$ deformation [7] 
of driving force, and misorientation dependence of boundary mobility. The superposition model demands abundant nucleation, whereas the compromise model corresponds to sparse nucleation. On the other hand, it has been observed that the statistical compromise model is able to explain the most prominent texture types in cubic metals (both FCC \& BCC) [32].

\section{The importance of recrystallization and deformed texture}

The grain orientations in polycrystal, are distributed with a certain preferred orientation. It has been observed that, most of the materials exhibit with some exact pattern in the orientations. Along with that there exists a tendency for the occurrence of particular orientations during crystallization from a melt and as well as by consecutive thermomechanical processes. This tendency is known as preferred orientation or, more precisely, texture. The importance of texture to materials holds in the fact that, many material properties are texture specific [33]. In a similar manner, during the process of recrystallization new texture evolves in the material which is different from the texture of deformed state; these new textures reflect thermo- mechanical processing history of the work piece.

FCC metals like $\mathrm{Cu}, \mathrm{Au}, \mathrm{Ag}, \mathrm{Al}$ are usually soft and ductile, which indicates that they can be bent and shaped easily. On the other hand, these metals show comparatively lower strength. The deformation textures of FCC metals are basically characterised by the stacking fault energy (SFE). For high SFE metals like aluminium the corresponding textures are known as pure metal or copper type rolling texture to separate it from textures evolved in low SFE value FCC metals. The influence of SFE on texture evolution is explained in terms of mechanism involved in the process of deformation. In case of metals with high to medium stacking fault energy the process of deformation is primarily dominated by slip of dislocations $[3,33,34]$. The fundamental pure metal textures are given by the Brass orientation $\{011\}<112>$, the Copper orientation $\{112\}<111>$ and the $S$ orientation $\{123\}$ $<634>[34,35]$. However, for the crystallographic models with twinning as well as for conventional models there are two types of rolling texture obtained; namely brass-type texture and the coppertype texture which are experimentally observed as well [44]. Table 4 shows texture components and fibers, which typically evolve in FCC metals during deformation.

Table 4. Texture components in rolled FCC metals [3]

\begin{tabular}{c|c|c|c|c|c} 
Texture Component, symbol & $\{\mathrm{hkl}\}$ & $<\mathrm{uvw}>$ & $\Phi_{1}\left[^{\circ}\right]$ & $\Phi_{2}\left[^{\circ}\right]$ & $\Phi_{3}\left[^{\circ}\right]$ \\
\hline Copper, C & 112 & 111 & 90 & 35 & 45 \\
S & 123 & 634 & 59 & 37 & 63 \\
Goss, G & 011 & 100 & 0 & 45 & 90 \\
Brass, B & 011 & 211 & 35 & 45 & 90 \\
Dillamore, D & $4,4,11$ & $11,11,8$ & 90 & 27 & 45 \\
Cube & 001 & 100 & 0 & 0 & 0
\end{tabular}

Table 5. Fibers in rolled FCC metals [3, 33]

\begin{tabular}{c|c} 
Fibre & Common axis of orientation \\
\hline$\alpha$ & $<011>/ / \mathrm{ND}$ \\
$\beta$ & $\{h, 1, h+1\}<\frac{h(h+1)}{3 / 4-h}, \frac{2 h(h+1)}{1 / 2-h}, \frac{h^{2}}{h-3 / 4}+\frac{2 h}{h-1 / 2}>$ \\
$\Gamma$ & $<111>/ / \mathrm{ND}$ \\
$\theta$ & $<001>/ / \mathrm{ND}$ \\
$\eta$ & $<001>/ / \mathrm{RD}$
\end{tabular}


The fiber as shown in Table 4 and 5 is a group of orientation with a common plane parallel to the particular macroscopic axis. Due to crystal symmetry, it is possible that one fiber may appear several times in the Euler space [33].

The range of recrystallization textures seen in FCC metals and alloys is much wider and more complex than is the case of the corresponding deformation textures, and under many conditions, the origin of the textures is still a matter of discussion. The formation of recrystallization texture is characterised not only by the formation as well as movement of high angle grain boundaries, which is accomplished by the process of nucleation and grain growth [3, 33, 34]. Along with that, there are various other factors that may affect the recrystallization texture in FCC metals. For example, we can discuss the effects of prior grain size, rolling reduction and annealing temperature. In case of 70:30 brass after annealing for 1 hour at $300{ }^{\circ} \mathrm{C}$ (low temperature) the texture of material cold rolled with $92 \%$ reduction changed from the normal $\{236\}<385>$ to $\{110\}<110>$ as the prior grain size increased, but the magnitude of the change was strain dependent and non-existent at $97 \%$ reduction. Annealing at high temperatures $\left(600{ }^{\circ} \mathrm{C}\right)$ led to a $\{113\}<332>$ texture for small grain sized material and high reductions. After low reductions the $\{110\}$ and more general $\{110\}$ orientations. The $\{110\}$ $<112>$ texture was present to higher strain levels as the grain size increased. It seems to be a probable case, that at high temperature $\{113\}<332>$ texture involved grain growth, and in the $97 \%$ rolled material, on the other hand when grain growth was limited by the specimen thickness and the short annealing times, the texture was $\{236\}<385>$. For all grain sizes investigated $(30-3000 \mu \mathrm{m})$ the texture of heavily rolled material was $\{236\}<385>$ after annealing at $300{ }^{\circ} \mathrm{C}$, and $\{113\}<332>$ for $600{ }^{\circ} \mathrm{C}$ annealing. These results illustrate the importance of grain growth effects on annealing textures [3]. However, considering the fact of orientation growth it has been reported by Liebmann that the growth of new grains during recrystallization is preferred in a particular orientation with respect to the deformed matrix [28]. For pure aluminium the preferred orientation and highest mobility is observed when, grain boundaries rotate with a relationship of approximately $40^{\circ}$ about a $<111>$ axis [36]. Taking account of all the effecting factors discussed above most common recrystallization texture in FCC system are listed below.

At the same time, it is one of the most striking features of recrystallization that the texture produced by heavy deformation can be completely modified by recrystallization. There are at least three different types of recrystallization texture known to be produced by recrystallization: a) at

Table 6. Texture components in rolled FCC metals [3]

\begin{tabular}{c|c|c|c|c|c}
$\begin{array}{c}\text { Texture Component } \\
\text { and Miller indices }\end{array}$ & $\{\mathrm{hkl}\}$ & $<\mathrm{uvw}>$ & $\Phi_{1}\left[^{\circ}\right]$ & $\Phi_{2}\left[^{\circ}\right]$ & $\Phi_{3}\left[^{\circ}\right]$ \\
\hline Cube & 001 & 100 & 0 & 0 & 0 \\
Cube $_{\mathrm{RD}}$ & 013 & 100 & 0 & 22 & 0 \\
Cube $_{\mathrm{ND}}$ & 001 & 310 & 22 & 0 & 0 \\
Cube-twin (first generation) & 122 & 212 & 27 & 48 & 27 \\
Goss & 011 & 100 & 0 & 45 & 0 \\
BR & 236 & 385 & 80 & 31 & 35 \\
U (transition) & 285 & 121 & 45 & 35 & 20 \\
R & 124 & 211 & 53 & 36 & 60 \\
P & 011 & 122 & 65 & 45 & 0 \\
Q & 013 & 231 & 45 & 15 & 10
\end{tabular}


one extreme the deformation texture components can be essentially retained, b) in other cases the texture can be strongly randomized and, finally, c) a component that is only a negligible fraction of the deformation can become an overwhelmingly dominant feature of the recrystallization texture. It has been observed that heavily cold rolled commercial pure Aluminium, containing a high density of iron-rich constituents, can give a significant deformation texture while high-purity Aluminium can give rise to a very strong new orientation, that of the cube $\{001\}<100>$ [37].

\section{Recent issues on recrystallization of FCC metals}

From 1881, when Kalischer first acknowledged the phenomenon of recrystallization to the current time a lot of progress has taken place in the field of studies of recrystallization [38]. This section is focused on recent revelations done in the field of recrystallization of FCC metals. It is focused mostly on thermomechanical treatment and microstructure control for the metals in interest.

It has been observed that high purity aluminium ( $>99.99 \% \mathrm{Al})$, copper $(99.995 \% \mathrm{Cu})$, and nickel $(99.988 \% \mathrm{Ni})$ shows dominant recrystallization cube texture under the following conditions [39]:

- A cube substructure must be present in the deformed matrix of the heavily rolled material.

- This cube texture must play the role of recrystallization nuclei.

- This cube nuclei should grow rapidly by means of migration of high angle boundaries.

- It is possible for the cube grains to grow at the expense of the other small grains because of the size effect, which makes the cube texture dominant and unique at the same time.

It has been observed that the strong cube texture can be obtained after the primary recrystallization under the above conditions, but the size of cube grains can also be larger than those of other grains. In this case, it is considered that the cube texture is strengthened by grain growth during further annealing and becomes a dominant final texture with the help of surface effect. Along with that, it is possible that some substructure with cube orientation has certain stability during the process of rolling and can remain in the deformed matrix after heavy rolling. This shows higher preference for the cube component in becoming recrystallization nuclei and growing in comparison to other substructures. All these characteristics of cube texture are closely related to the condition of crystallographic geometry in rolling deformation and lead to a final dominant cube texture [39].

The cube orientations are a finite, but very small component of the usual FCC rolling texture. On recrystallization after suitable deformation, the minor cube component of the deformation texture in some cases becomes the dominant part of the recrystallization texture. There are some observations done about the dominating cube component, given as [3, 40]:

- The increase in cube texture is initiated by the enhancing the quantity of cube grains, as well as by the decrease in their divergence from the perfect cube orientation.

- The cube grains tend to nucleate through deformation bands along the rolling direction.

- On average, each cube grain tends to split into seven misoriented bands throughout the process of plane-strain compression. On the other hand, these grains tend to break into three misoriented bands during plane-strain extrusion.

- Each grain with primary cube structure tends to give rise to at least one deformed cube band while deformed. Which causes the spacing between cube structures to decrease in a predictable manner with strain.

- The cube grains obtained in final texture enhances greatly in strength as prior strain was increased [40]. 
It has been documented that the $\beta$-fibre can be exactly described in the first, second and third Euler subspaces by the analytical expression given below [41]:

$$
\{h, 1, h+1\}<\frac{h(h+1)}{3 / 4-h}, \frac{2 h(h+1)}{1 / 2-h}, \frac{h^{2}}{h-3 / 4}+\frac{2 h}{h-1 / 2}>,
$$

that describes the rolling texture in both pure metals and alloys of medium and high SFE with FCC structure in spite of the varieties in the chemical composition and thermo-mechanical processing parameters [41]. At the same time, asymmetric rolling of FCC metals like Al tend to provide a finer recrystallized grain structure as compared to conventionally produced material. According to Sidor and Kestens for High SFE FCC metals like Al the larger amount of accumulated strain leads to an increased population of nuclei, which causes fine-grained structures [42].

It has been observed that strain mode applied in both hot and cold rolling processes significantly affects the final recrystallization texture when experiment has been conducted on Aluminium alloy of 6xxx series. The recrystallization textures produced in the Asymmetric Rolling process improve the normal anisotropy, whereas the in-plane anisotropy does not benefit momentously from the Asymmetric rolling process. Results of crystal plasticity calculations show that an improved normal anisotropy in asymmetrically rolled sheets ensures an increased limiting drawing ratio, which is in favour of enhanced formability [43].

\section{Conclusions}

Formation of recrystallization texture, in general, and FCC cube recrystallization texture, specifically, is of considerable scientific and industrial interest. As the substitution of steel with light metals is an effective way to reduce the weight of car bodies. FCC metals like Aluminium alloys are an attractive candidate for automotive applications because of their favourable strength-to-weight ratio and high corrosion resistance characteristic. However, the soft and ductile nature of FCC metals makes it difficult to process during specific forming procedures.

It can be concluded that a large volume of scientific and technological knowledge has been accumulated in the field of study. Although various scientific aspects still need further attention. Research till the date in the field of analysis of recrystallization texture avails us with the knowledge of control over the microstructure of metallic materials during its thermomechanical processing. Hence, using the idea of texture control in various FCC mechanical properties of the respective metals can be improved.

\section{References}

[1] E. Orowan, To crystal plasticity II, Magazine for Physics 89, 1934, pp. 614-633. CrossRef

[2] F.J. Humphreys, Nucleation in Recrystallization, Materials Science Forum 467-470, 2004, pp. 107-116. CrossRef

[3] F.J. Humphreys, G.S. Rohrer, A. Rollett, Recrystallization and Related Annealing Phenomena, Third edition, Elsevier: Amsterdam, The Netherlands, 2017.

[4] R.D. Doherty, D.A. Hughes, F.J. Humphreys, J.J. Jonas, D. Juul Jensen, M.E. Kassner, W.E. King, T.R. McNelley, H.J. McQueen, A.D. Rollett, Current issues in recrystallization:a review, Materials Science and Engineering 238, 1997, pp. 219-274. CrossRef

[5] W.D. Callister, D.G. Rethwisch, Materials Science and Engineering: An Introduction, Seventh Edition, John Wiley \& Sons, New York, 2007. 
[6] K. Huang, R.E. Logé, A review of dynamic recrystallization phenomena in metallic materials, Materials \& Design 111, 2016, pp. 548-574. CrossRef

[7] P.R. Rios, F.S. Jr; H.R.Z. Sandim, R.L. Plaut, A.F. Padilha, Nucleation and growth during recrystallization, Materials Research 8, 2005, pp. 225-238. CrossRef

[8] A.N. Kolmogorov, On the Statistical Theory of Crystallization of Metals, Bulletin of the Academy of Sciences of the USSR Ser. Math 3, 1937, pp. 355-359. CrossRef

[9] W.A. Johnson, R.F. Mehl, Reaction kinetics in processes of nucleation and growth, Transactions of the American Institute of Mining and Metallurgical Engineers 135, 1939, pp. 416-442.

[10] M. Avrami, Granulation, Phase Change and Microstructure Kinetics of Phase Change III, The Journal of Chemical Physics 9, 1941, pp. 177-184. CrossRef

[11] M. Avrami, Kinetics of Phase Change II, Transformation-Time Relations for Random Distribution of Nuclei, The Journal of Chemical Physics 8, 1940, pp. 212-224. CrossRef

[12] M. Avrami, Kinetics of Phase Change I, General Theory, The Journal of Chemical Physics 7, 1939, 1103-1112. CrossRef

[13] R.F. Mehl, ASM Metals Handbook, ASM, Metals Park, Ohio, 1948.

[14] J.E. Burke, D. Turnbull, Recrystallization and grain growth, Progress in Metal Physics 3, 1952, pp. 220-292. CrossRef

[15] I.L. Dillamore, H. Katoh, The Mechanisms of Recrystallization in Cubic Metals with Particular Reference to Their Orientation-Dependence, Material Science 8, 1974, pp.73-83. CrossRef

[16] W.R. Hibbard, W.R. Tully, The effect of orientation on the recrystallization kinetics of coldrolled single crystals, AIME TRANS 221, 1961, pp. 336-343.

[17] K. Brown, M. Hatherly, Rolling and recrystallization textures of copper single crystals, Journal of the Institute of Metals 98, 1970, pp. 310-317.

[18] K. Brown, M. Hatherly, Recrystallization kinetics of rolled copper single crystals, Journal of the Institute of Metals 98, 1970, pp. 317-320.

[19] J.C. Blade, A.J. Bryant, A.T. Thomas, Alloy composition and microstructure control in relation to mechanical working for aluminium alloys, Metals Technology 3, 1976, pp. 380-386. CrossRef

[20] D.R. Barraclough, C.M. Sellars, Static recrystallization and restoration after hot deformation of type 304 stainless steel, Metal Science 13,1979, pp. 257-268. CrossRef

[21] J.W. Christian, The Theory of Transformations in Metals and Alloys, First edition, Pergamon, Oxford, 2002. CrossRef

[22] P. Cizek, F. Bai, E.J. Palmiere, W. M. Rainforth, EBSD study of the orientation dependence of substructure characteristics in a model Fe-30wt\% Ni alloy subjected to hot deformation, Journal of Microscopy 217, 2005, pp. 138-151. CrossRef

[23] R.A. Vandermeer, D.J. Jensen, The Migration of High Angle Grain Boundaries during Recrystallization, Interface Science 6, 1998, pp. 95-104. CrossRef 
[24] M. Cook, T.L. Richards, The Structural Changes in Copper Effected by Cold Rolling and Annealing, Journal of the Institute of Metals 66, 1940.

[25] J.S. Bowles, and W. Boas, The effect of crystal arrangement on secondary recrystallization in metals, Journal of the Institute of Metals 74, 1948, pp. 501-519.

[26] P.A. Beck, P.R. Sperry, H. Hu, The orientation dependence of the rate of boundary migration, Journal of Applied Physics 21, 1950, pp. 420-425. CrossRef

[27] M.L. Kronberg, F.H. Wilson, Secondary recrystallization in copper, Transactions of the Metallurgical Society of AIME 185, 1949, pp. 501-514.

[28] B. Liebman, K. Lücke, G. Masing, Untersuchung über die Orientierungsabhängigkeit der Wachstumsgeschwindigkeit bei der primären Rekristallisation von Aluminium-Einkristallen, International Journal of Materials Research 47, 1956, pp. 57-63. CrossRef

[29] K.T. Aust, J.W. Rutter, Grain boundary migration in high-purity lead and dilute lead-tin alloys, Transactions of the Metallurgical Society of AIME 215,1959, pp. 119-127.

[30] W.A. Anderson, R.F. Mehl, Recrystallization of aluminum in terms of the rate of nucleation and the rate of growth, Trans. AIME 161, 1945.

[31] H. Hallberg, Approaches to Modeling of Recrystallization, Metals 1, 2011, pp. 16-48. CrossRef

[32] H.J. Bunge, U. Kohler, Modelling Primary Recrystallization in fcc and bcc Metals by Oriented Nucleation and Growth With the Statistical Compromise Model, Texture, Stress, and Microstructure 28, 1997, pp. 231-259. CrossRef

[33] O. Engler, V. Randle, Introduction to texture analysis: macrotexture, microtexture and orientation mapping, Second Edition, CRC Press/ Taylor \& Francis, Boca Raton, 2009. CrossRef

[34] O. Engler, K. Lacke, Mechanisms of recrystallization texture formation in aluminium alloys, Scripta Metallurgica et Materialia 27, 1992, pp. 1527-1532. CrossRef

[35] J. Hirsch, K. Lücke, Mechanism of deformation and development of rolling textures in polycrystalline fcc metals - I. Description of rolling texture development in homogeneous CuZn alloys, Acta Metallurgica 36, 1988, pp. 2863-2882. CrossRef

[36] D.A. Molodov, U. Czubayko, G. Gottstein, L.S. Shvindlerman, Mobility of $<111>$ tilt grain boundaries in the vicinity of the special misorientation $\sum=7$ in bicrystals of pure aluminium, Scripta Metallurgica et Materialia 32, 1995, pp. 529-534. CrossRef

[37] R.D. Doherty, Recrystallization and texture, Progress in Materials Science 42, 1997, pp. 39-58. CrossRef

[38] S. Kalischer, Ueber die Molekularstruktur der Metalle, Berichte der deutschen chemischen Gesellschaft 15, 1882, pp. 702-712. CrossRef

[39] W. Mao, Formation of Recrystallization Cube Texture in High Purity Face-Centered Cubic Metal Sheets, Journal of Materials Engineering and Performance 8, 1999, pp. 556-560. CrossRef 
[40] I. Samajdar, R.D. Doherty, Cube recrystallization texture in warm deformed aluminum: understanding and prediction, Acta Materialia 46, 1998, pp. 3145-3158. CrossRef

[41] J.J. Sidor, L.A.I. Kestens, Analytical description of rolling textures in face-centred-cubic metals, Scripta Materialia 68, 2013, pp. 273-276. CrossRef

[42] J. Sidor, R.H. Petrova, L.A.I. Kestens, Deformation, recrystallization and plastic anisotropy of asymmetrically rolled aluminum sheets, Materials Science and Engineering: A 528, 2010, pp. 413-424. CrossRef

[43] J.J. Sidor, R.H. Petrov, L.A.I. Kestens, Texture-Induced Anisotropy in Asymmetrically Rolled Aluminium Alloys, Advanced Engineering Materials 13, 2011, pp. 949-954. CrossRef

[44] U.F. Kocks, C.N. Tomé, H-R. Wenk, Texture and Anisotropy, First edition, Cambridge University Press, Cambridge, 1998. 